\title{
COVID-19 in Rural China: Features, Challenges and Implications for the Healthcare System
}

Jie Wang ${ }^{1,2}$

Ruilian Zhang $\mathbb{D}^{3}$

'School of Public Administration, Hohai University, Nanjing, 21 I 100, People's Republic of China; ${ }^{2}$ School of Law, Anhui Normal University, Wuhu, Anhui, 241002, China; ${ }^{3}$ Sustainable Minerals Institute, The University of Queensland, Brisbane, 4072, Australia
Correspondence: Ruilian Zhang Sustainable Minerals Institute, The University of Queensland, Brisbane, 4072, Australia

Tel +6/48I I 20982

Email ruilian.zhang@uq.edu.au

\begin{abstract}
A public health crisis is a "touchstone" for testing the ability and capacity of rural and urban health systems. In the context of coronavirus disease 2019 (COVID-19) in China, we track the features, challenges, and implications of the temporary disruption of the health system in rural China and its response to this major public health crisis. We examine the general content and logic of village pandemic prevention and control regarding COVID-19 through a case study. Accordingly, we identify the challenges to the rural health system, including logic failure and its causes. It is strongly suggested that the government strengthen rural health system reform, balance medical services between rural and urban areas, and strengthen public health awareness and education.
\end{abstract}

Keywords: public health crisis, rural area, health system, challenges, COVID-19

\section{Introduction}

International relations, the governance of China and world patterns will inevitably change in the pandemic era. As the greatest change in the century, the pandemic can be said to be a catalyst accelerating the renewal and reorganization of elements worldwide. ${ }^{1}$

Since 2020, the coronavirus disease 2019 (COVID-19) pandemic has rapidly spread across the world, and 100 million cases, affecting both the Northern and Southern Hemispheres, were confirmed by January $2021 .^{2}$ Sporadic local cases and broader pandemic influences are reported in many provinces in China. The pandemic situation is characterized by a long duration, wide range and fast transmission speed, with a large proportion of elderly patients and a high proportion of patients in rural areas. In some places, community transmission and multigeneration transmission have occurred, and the prevention and control situation is complex and severe. $^{3}$ In this regard, the national health protection committee has taken 6 measures to prevent and control the pandemic situation in rural areas, such as raising awareness of COVID-19 reporting in township hospitals, village and private clinics; highlighting the monitoring of respiratory symptoms, such as fever, dry cough and sore throat; emphasizing the responsibility of the first diagnosis; arranging contact tracing for vulnerable groups; establishing epidemiological investigation teams; and quickly carrying out comprehensive epidemic prevention and control efforts.

Ulrich Beck uses the word "risk society" to describe the characteristics of modern society. ${ }^{4}$ With the rapid development of society, social contradictions involving population, resources and environment are increasing, social injustice is enlarging, 
and all kinds of emergencies are occurring frequently. In modern society, human beings are faced with a variety of risks. Health and life risks often happen without warning. ${ }^{5}$ In a risk society, it is difficult to accurately predict risk.

Pandemic prevention and control in rural areas represents an important part of the whole prevention and control system, and the basic unit of prevention and control is the village. ${ }^{6}$ The village is one of the ends of pandemic prevention and control, which often reflects the political ecology of the grassroots society. In the "pandemic era", weaving dense protective nets and building solid isolation defences are the main countermeasures for pandemic prevention and control. The pandemic situation has tested the public healthcare "immune system" of Chinese cities and led to the gradual construction of villages' pandemic response systems. ${ }^{7}$ What is the current situation of pandemic prevention and control in villages? Can the "immune system" of the village play a role in addressing the pandemic situation? Village pandemic risk responses are an important part of China's healthcare system construction, which tests the modernization of the national governance system and governance capacity. The modernization of governance should be a major issue that is developed in both urban and rural areas. We argue that the prevention and control features, challenges and implications associated with COVID-19 have been overlooked in rural areas. Therefore, we explore the features, challenges and implications posed by the COVID-19 pandemic for the healthcare system in rural China. We discuss the flaws that existed in the village healthcare system before the pandemic and the additional burdens the pandemic has imposed. Four sections follow this introduction. Section 2 introduces the general features and logic of rural areas' response to COVID-19. Section 3 explains the challenges facing the healthcare system in rural China. Section 4 presents the implications for improving public healthcare system emergency management in rural China. Section 5 concludes the paper.

\section{COVID-19 in Rural China}

\section{Features of Village Pandemic Prevention and Control}

The main strategy of pandemic prevention and control in villages is to organize special teams to carry out card setting, patrol, isolation, and continuous monitoring. In principle, only one entrance to the village is set up, and isolation facilities, such as safety barriers, are set up at other intersections, with eye-catching isolation signs. ${ }^{8}$

Detailed measures of rural pandemic prevention and control:

The contents of registration include name, ID card, place of residence, permanent residence, telephone number, licence plate number, any contact with or visit to key pandemic areas, and any history of contact with an infected individual, along with the measurement of body temperature. The registration can be simplified according to the situation. Cases of non-cooperation are immediately reported to the local police, and compulsory measures are taken when necessary. Various publicity methods, such as loudspeakers, WeChat groups, gongs, publicity cars, leaflets and banners, are used to improve villagers' awareness of the pandemic prevention and control.

Individuals are stationed at each entrance to take temperatures and register entrants. In the process of dealing with this major public health event, many rural governance subjects in China have actively participated in the prevention and control efforts. Their efforts at the grassroots level have effectively restrained the spread of infection and reduced the pandemic risk. However, the major public health event has had comprehensive and diverse impacts on rural society. The core of rural social governance ability and level lies in whether it can effectively prevent and control primary risks. Second, it is unclear whether rural governance can effectively resolve secondary social risks to further prevent secondary crises. Due to the limited overall governance capacity in rural areas, rural areas are vulnerable to all kinds of social risks during a major pandemic. ${ }^{9}$ If social risk is not addressed, it can affect not only the comprehensive improvement in rural public crisis response ability but also the sustainable, healthy and stable development of rural society. This emphasizes the higher requirements for rural social governance in the pandemic era. ${ }^{10}$

The author's hometown is a village in Northern China near the capital. At the beginning of 2020, when the pandemic was rampant, the prevention and control of the pandemic in the village was similar to that in the vast majority of Chinese villages, with the only difference concerning the degree of implementation. ${ }^{11}$

The village team actively places under quarantine individuals who live in the key pandemic areas of the village, who have recently returned from the key pandemic areas or who have had contact with an infected individual and 
mobilizes the villagers to implement timely prevention and control measures. ${ }^{12}$

\section{The Logic of Village Pandemic Prevention and Control: Inequality Between Inside and Outside Groups}

The logic of village pandemic prevention and control concerns the inequality between inside and outside groups. The essence of the strategy is to temporarily cut off the links with the risk sources outside the village to reduce the risk. However, the specific implementation of the pandemic prevention and control strategy in villages differs for people living inside and outside the village, with stricter implementation for people outside the village, especially for villages in high-risk pandemic areas. ${ }^{13}$ For example, people are forbidden or persuaded not to return to the village, or the road to the village is even obstructed. However, there is certain flexibility for people inside and outside the village. Especially in rural areas, when villagers demand or quarrel, the requirements are often relaxed. For example, Wang and $\mathrm{Bu}$ analysed the characteristics of pandemic prevention and control in Western $\mathrm{Y}$ village. ${ }^{14}$ At the time of the funeral of a Mr. Wang on January 24, 2020 , during the severe development of the pandemic, village cadres advised families not to treat or receive gifts in order to prevent the gathering of many people. However, while externally, measures were taken to strictly follow the rules, internally, "human feelings" and "face" were emphasized, and Mr. Wang's funeral was still held as usual. Even during the severe period of the pandemic, 300 people participated in a funeral, but not all villagers were treated equally. ${ }^{15}$ In the countryside, the people living in a village and in the nearby area are regarded as a whole and are considered a close group, within which contact is safe. The external groups in other places are divided into unsafe and risky groups. The ethics and rules differ inside and outside Chinese rural society. The boundary of individual belonging is changeable and flexible. ${ }^{15,16,17,18}$

\section{Challenges for the Rural Healthcare System}

\section{Logic Failure of Village Pandemic Prevention and Control Efforts}

The logic of village pandemic prevention and control concerns the inequality between groups inside and outside the village. Logic failure is the lack of a rapid response mechanism in village pandemic prevention and control. There is often a wide time gap between the emergence and discovery of the pandemic situation, which promotes the spread of the pandemic.

In the high-risk period, the pandemic threatens not only the lives of individuals but also the survival of the whole village. Villages must deal with the risk through strong governance and the isolation of the village from the outside. ${ }^{19}$ When the risk level reduces, villages adjust their boundaries and become more open to the outside world, while when the pandemic rebounds, villages again become closed to the outside in response to the pervasive risk. After the pandemic situation becomes stable, the difference between the internal and external prevention and control strategies gradually reduces. ${ }^{20}$ Rural areas are undeniably the weakest link in China's pandemic prevention. The case of Y village in Hebei Province in 2021, described below, reflects the failure of the village prevention and control logic.

$\mathrm{Y}$ village is located in Shijiazhuang City, Hebei Province, with an agricultural population of more than 4700 . Y village is characterized by a relatively good economic situation and convenient transportation. ${ }^{14}$ There are several bus stops at the entrance of the village, and the surrounding residents take the bus to reach the village. A resident of $Y$ village stated that on the third and eighth days of each month, vegetable markets are set up on both sides of the road at the entrance of Y village, and residents from neighbouring villages come. The village is close to Zhengding Airport, with a straight-line distance of approximately $10 \mathrm{~km}$. As of January 18, 2021, there were 800 local confirmed cases and 168 asymptomatic infections in Hebei Province. A total of 766 confirmed cases have been found in Shijiazhuang City, which has become a crisis area. The first confirmed case in Hebei is not "patient zero". According to the Hebei Center for Disease Control and Prevention, the first estimated case in Hebei was as early as December 15, 2020. The virus has been spreading recessively among villages for some time. ${ }^{14}$ After January 12, the number of newly diagnosed local cases exceeded 100 for four consecutive days. Local outbreaks have arisen in Heilongjiang, Beijing, Liaoning and other places.

$\mathrm{Y}$ village and two villages less than $2 \mathrm{~km}$ away accounted for approximately $50 \%$ of the total cases in Shijiazhuang. These villages are all located within 10 kilometres of Shijiazhuang Zhengding airport. Most young people in the villages prefer the city and migrate to 
work, leaving behind most of the elderly individuals, women and children. As of January 18, most of the confirmed cases in Shijiazhuang were farmers. The average age of the patients was 45 years old, and $27 \%$ of the patients were over 60 years old. The number of female cases was 1.5 times the number of male cases, and there were nearly 70 confirmed cases in primary and secondary school students. Geographical conditions contribute to the high concentration of the population. Since the villages are not far away from each other, their residents have close contact with each other. One of the important activities is going to the market. According to contact tracing efforts, on January 1, 2021, 13 individuals with confirmed infection from nearby villages went to the market at $\mathrm{Y}$ village, as villagers from other towns often drive to the market in their private cars. In addition to going to the market, an important activity for housewives is attending wedding banquets. Women represented a high proportion of the confirmed cases because they participate in more social activities than men do. In wedding ceremonies, women in the village act as drummers and play various musical instruments. There is a local custom of holding weddings at the end of the year. A total of 124 confirmed cases participated in a wedding banquet in Shijiazhuang that lasted from the end of 2020 to the beginning of 2021 . A 44-year-old woman from $Y$ village participated in three wedding banquets in just four days from December 30, 2020, to January 2, 2021. In addition, religious activities can easily lead to the spread of the pandemic. Before the outbreak of the pandemic, some people had gathered at the home of a family in the village for religious activities, which, like other gatherings, easily facilitated the spread of the pandemic.

Most of the villagers said that since the domestic pandemic was basically under control in the summer of 2020 , they relaxed their vigilance. This is reflected in the increase in party activities and the decision not to wear masks during hot weather. People treat cough and headache as minor diseases and may not go to the hospital. ${ }^{21}$ Moreover, rural residents' low awareness of medical treatment, poor medical habits and insufficient access to highquality medical resources are important reasons for the outbreak. Rural primary medical institutions play an important role as gatekeepers, as do village clinics and township health centres, which are superior management units. The current public information of the Hebei epidemiological survey indicates that at least 62 people came to such medical institutions for treatment and medicine due to obvious symptoms, such as cough, headache and fever, but they did not arouse due vigilance. In reality, due to their limited conditions, rural primary clinics have no ability to diagnose patients. However, their main role should be to find suspected patients in time and report them to the hospital. The village's prevention and control logic has failed in this case. Primary medical institutions do not play a "sentinel" role in the actual diagnosis and treatment process. ${ }^{22}$

\section{The Causes of the Logic Failure of Village Pandemic Prevention and Control}

The direct causes of the logic failure of village pandemic prevention and control are traffic, culture, wedding banquets, geographical location, and population structure. ${ }^{14}$ These factors can be catalysts that intensify the spread of the pandemic in Y village. For example, convenient transportation and geographical location contribute to the quick spread of the pandemic. The gathering of people, for example, at the market and wedding banquets, further increases the number of people infected. Regarding the population structure, young people go out to work, leaving behind the elderly individuals, women and children, who generally lack information sources and have little understanding of the pandemic. ${ }^{23}$

The indirect causes of the logic failure of village pandemic prevention and control are the inadequately equipped teams in the rural pandemic prevention system. For example, village-barefoot doctors are growing older and gradually withdrawing from front-line health work. Young college graduates are unwilling to stay in the countryside, and there is a shortage of talent in rural areas. ${ }^{24}$ In 2018, doctors aged 60 or older represented more than a quarter of rural doctors in China and even $80 \%$ in some townships, and only $5 \%$ of rural doctors were under 35 years old. Moreover, the phenomena of low medical history, low professional title and low professional level are common among village healthcare personnel. In 2018 , only $15 \%$ of personnel had a bachelor's degree or above. ${ }^{1}$ Rural doctors account for more than $1 / 3$ of the grassroots medical staff, and they are the main force of rural grassroots health prevention and control by virtue of their familiarity with villagers. However, it is undeniable that elderly grassroots medical workers offer little support for the prevention and control of infectious diseases. Elderly individuals are susceptible to COVID-19, and the probability of cross infection is high in the process of 
door-to-door service. ${ }^{2}$ Second, elderly village doctors find it difficult to operate the many new information technologies for prevention and control, which reflects the deep weakness of the rural public health system. ${ }^{14}$

\section{Implications for Rural Healthcare System Development}

The prevention and control of the pandemic ultimately needs the establishment of a multidimensional and deep governance system. ${ }^{1}$ In the post-pandemic era, the reconstruction of multiple prevention and control strategies and promotion of the modernization of public healthcare governance are important to address many risks in the future. It is suggested to reform the medical service supply system in rural areas, improve the emergency response mechanism for major public health events and strengthen health publicity and education.

\section{Reform the Medical Service Supply System in Rural Areas}

During the outbreak of a major pandemic, the efficient and orderly operation of medical emergency treatment systems is very important to improve the admission rate and reduce the infection rate and mortality. ${ }^{15}$ Primary medical institutions, as basic public health services in China, are responsible for the reporting and management of infectious diseases and public health emergencies. ${ }^{9}$ Therefore, it is necessary to consolidate the "gatekeeper" role of primary medical institutions. In the case of major public health emergencies, the hierarchical diagnosis and treatment system should be enforced, the medical order should be optimized, and hierarchical, separate treatment should be implemented. Therefore, it is necessary to increase investment and strengthen the construction of primary medical institutions. ${ }^{7}$ First, in the construction of primary medical institutions, pre-screening triage and fever clinics are necessary to undertake the functions of disease screening and patient classification management during health emergencies. Second, the use of electronic health records and the grid management of residents' health and the cooperation between the community and pandemic prevention and control institutions can support community pandemic prevention and control. ${ }^{8,19}$

Second, it is important to strengthen the public health function of medical institutions, promote the linkage of prevention control treatment and develop synergistic effects. Medical institutions themselves are also an integral part of the disease prevention and control system. ${ }^{2,3}$ They are responsible for the monitoring, reporting, emergency treatment of infectious diseases and public health issues, and prevention and control of infectious diseases in their responsible areas. Unfortunately, these public health functions have not been strictly defined at the legal level and have not been emphasized in the reform of public hospitals. ${ }^{4}$ The awareness of infectious disease prevention and control of medical institutions and clinicians needs to be strengthened; moreover, the medical service system and the public health system lack regular joint working mechanisms. ${ }^{20}$ Therefore, the public health function of the medical service system should be strengthened and supplemented by incentive mechanisms. Moreover, it is necessary to improve the communication and coordination mechanism within the public health system, realize information exchange and sharing, and build the working mode of medical prevention integration. For the prevention and control of infectious diseases and public health emergencies, the sequence of prevention, control, and treatment is formed, involving information sharing, personnel training, emergency drills, and scientific research cooperation, to develop synergistic effects. ${ }^{14,15}$

\section{Improve the Emergency Response Mechanism for Major Public Health Events}

First the unitary management pattern should be eliminated and replaced with a mechanism for public, social and market participation. ${ }^{2}$ In the past four decades, social forces have developed unprecedentedly and played an increasingly important role in the social and economic life in China. However, the existing emergency management mechanism is designed based on the concept of an omnipotent government, and emergency management mainly depends on the actions of the government and relevant departments. ${ }^{3,4}$ In practice, due to the poor participation mechanism, economic and social organizations and the public cannot effectively cooperate with the government but play a limited role. ${ }^{4,5}$ Therefore, the unitary management pattern must be replaced by a social governance mechanism for major public health emergencies to enable the participation of the market, society and citizens. The public, society and market participation mechanism should be established for support during major public health emergencies. It integrates vertical social integration with horizontal social cooperation under the guidance of 
the government. ${ }^{19,20}$ In the whole chain of emergency management, a pattern of interaction among the government, the market and society should form a mutually complementary and efficient coordination under the guidance of the government. In the prevention and control of a pandemic, mass prevention and treatment measures represent an innovative mechanism of social participation. After the pandemic crisis, these measures need to be further refined and improved to become an important part of the emergency mechanism for major public health emergencies. ${ }^{1,2}$

Second, a modern emergency material reserve system needs to be built. For example, in January 2021, citizens of Tonghua City, Jilin Province, reported on major media and network platforms that the closed management was caught off guard, daily necessities and food were seriously lacking, basic life could not be guaranteed, and hotlines were inaccessible. In response to the query, at a press conference held on the morning of January 24th, Vice Mayor Jiang Haiyan of Tonghua City apologized on behalf of the municipal party committee and the municipal government for the inconvenience caused by the untimely distribution of people's living materials. This highlights the importance of addressing the shortcomings of the existing classification, establishing special reserves for various departments and scientifically determining the demand for reserve materials by category, scale and structure based on big data technology and comprehensive risk analysis. Utilizing the unified national emergency material procurement and supply system, integrating all special reserve resources, stocking emergency supplies in central locations, and improving and guaranteeing the operational efficiency of the material reserve system are important steps.

\section{Strengthen Health Publicity and Education}

First, it is strongly suggested to build a national health education system and advance emergency management. The key to dealing with major public health emergencies is prevention. ${ }^{2}$ Emergency management is the most economical and effective method to build a national health education system and improve national health literacy. Health education has long been one of the important contents of public health services in China, but in practice, it is often a mere formality. ${ }^{1,3}$ Government investment should be increased and adequate funding be guaranteed to support the organizational system of health education institutions and provide health education to the whole population, and health education should be integrated into schools at all levels. Starting from childhood, health education should be strengthened for primary and secondary school students. ${ }^{5}$ Second, the prevention and control of major infectious diseases and emergency education should be strengthened, and publicity and education work should be normalized. In recent years, the focus of health education has gradually shifted from early infectious disease prevention and control to chronic disease prevention and health management. The pandemic represents a tragic warning: major infectious diseases have not left the stage of history. ${ }^{6,7}$ In particular, urbanization, ageing and globalization have made infectious diseases more active, and their return is inevitable. It is important to start from the source, strengthen publicity and education, improve awareness of protection, and change individuals' behaviour. ${ }^{21}$ Therefore, routine propaganda and education should pay equal attention to the prevention and control of major infectious diseases, chronic diseases and health management. In addition, emergency education on major infectious diseases should be strengthened to improve people's health literacy in emergencies. ${ }^{15,25}$

\section{Conclusion}

COVID-19 not only threatens human health but also has major adverse effects on social development. In particular, in rural areas of China, the government should pay more attention to the health system due to the failure of COVID19 prevention and control efforts. At present, COVID-19 has spread to more than 100 countries and regions. The World Health Organization has upgraded COVID-19 to a global pandemic, and COVID-19 has had a serious impact on people's lives and health in both rural and urban regions. Many countries failed to achieve effective prevention and control in the early stage of the pandemic, leading to the rapid spread of the disease. Our review of the failures of village pandemic prevention and control efforts and their causes in China indicate that rural areas are highly vulnerable to public health crises. This reminds us that when facing the second wave of COVID-19 or during the post-pandemic era, it is important to pursue the correct path to save lives and to enable economic recovery by reviewing possible improvements to the healthcare system in rural regions around the world. We believe that the prevention and control of COVID-19 in rural regions is worthy of discussion. Future directions for research mainly include the economic sacrifice of preventing and controlling the pandemic in rural regions and the potential sacrifice of villagers' privacy in the process of tracking the disease. Therefore, it is crucial to find the optimal balance to control the pandemic without incurring 
major economic or personal sacrifices in rural regions. The limitation of this study is that we focus on specific cases without considering the diverse social, economic and environmental background. ${ }^{1}$

\section{Abbreviation}

COVID-19, coronavirus disease 2019.

\section{Acknowledgments}

This research was funded by the Research Innovation Program for College Graduates of Jiangsu Province, grant number KYZZ_0158.

\section{Disclosure}

The authors report no conflicts of interest in this work.

\section{References}

1. Xing C, Zhang R. COVID-19 in China: responses, challenges and implications for the health system. Healthcare. 2021;9(1):82. doi: $10.3390 /$ healthcare9010082

2. Zhang J, Zhang R. COVID-19 in China: power, transparency and governance in public health crisis. Healthcare. 2020;8(3):288 doi:10.3390/healthcare 8030288

3. Sun Z, Yang B, Zhang R, Cheng X. Influencing factors of understanding COVID-19 risks and coping behaviors among the elderly population. Int $J$ Environ Res Public Health. 2020;17:5889. doi:10.3390/ijerph17165889

4. Ulrich B. Risk Society: Towards a New Modernity. Translated by Ritter, Mark. London: Sage Publications; 1992.

5. Yip W, Hsiao WC. The Chinese health system at a crossroads. Health Aff. 2008;27(2):460-468. doi:10.1377/hlthaff.27.2.460

6. Yip W, Hsiao WC. What drove the cycles of Chinese health system reforms? Health Syst Reform. 2015;1:52-61. doi:10.4161/ 23288604.2014.995005

7. Brixi H, Mu Y, Targa B, Hipgrave D. Equity and Public Governance in Health System Reform: Challenges and Opportunities for China. Washington, D.C.: The World Bank; 2011. doi:10.1596/1813-94505530

8. Zhou XD, Li L, Hesketh T. Health system reform in rural China: voices of healthworkers and service-users. Soc Sci Med. 2014;117:134-141. doi:10.1016/j.socscimed.2014.07.040

9. Gianfredi V, Balzarini F, Gola M, et al. Leadership in public health: opportunities for young generations within scientific associations and the experience of the "Academy of Young Leaders". Front Public Health. 2019;7:378. doi:10.3389/fpubh.2019.00378
10. Hipgrave D, Guo S, Mu Y, et al. Chinese-style decentralization and health system reform. PLoS Med. 2012;9(11):e1001337. doi:10.1371/ journal.pmed.1001337

11. Burki T. China's successful control of COVID-19. Lancet Infect Dis. 2020;20:1240-1241. doi:10.1016/S1473-309930800-8

12. Yu X, Li C, Shi Y, Yu M. Pharmaceutical supply chain in China: current issues and implications for health system reform. Health Policy. 2010;97(1):8-15. doi:10.1016/j.healthpol.2010.02.010

13. Heena S, Hunny S. Role of social media during the COVID-19 pandemic: beneficial, destructive, or reconstructive? Int. $J$ Acad Med. 2020;6:70-75. doi:10.4103/IJAM.IJAM 50 20

14. Wang $\mathrm{Y}, \mathrm{Bu} \mathrm{X}$. The logic of village pandemic prevention and control under the background of risk society. Soc Sci Res. 2021;1(1):54-61.

15. Kraemer MUG, Yang C-H, Gutierrez B, et al.; Open COVID-19 Data Working Group. The effect of human mobility and control measures on the COVID-19 epidemic in China. Science. 2020;368 (6490):493-497. doi:10.1126/science.abb4218.

16. Mo Y, Deng L, Zhang L, et al. Work stress among Chinese nurses to support Wuhan in fighting against COVID-19 epidemic. J Nurs Manag. 2020;28:1002-1009. doi:10.1111/jonm.13014

17. Hopman J, Allegranzi B, Mehtar S. Managing COVID-19 in lowand middle-income countries. JAMA. 2020;323(16):1549. doi:10.1001/jama.2020.4169

18. Li X, Lu J, Hu S, et al. The primary health-care system in China. Lancet. 2017;390:2584-2594. doi:10.1016/S0140-673633109-4

19. Pan A, Liu L, Wang C, et al. Association of public health interventions with the epidemiology of the COVID-19 outbreak in Wuhan, China. JAMA. 2020;323:1915. doi:10.1001/jama.2020.6130

20. Sun Z, Cheng X, Zhang R, Yang B. Factors influencing rumour re-spreading in a public health crisis by the middle-aged and elderly populations. Int J Environ Res Public Health. 2020;17:6542. doi:10.3390/ijerph17186542

21. Yuan B, Jian W, He L, Wang B, Balabanova D. The role of health system governance in strengthening the rural health insurance system in China. Int J Equity Health. 2017;16:44. doi:10.1186/s12939-0170542-x

22. Tan W, Hao F, McIntyre RS, et al. Is returning to work during the COVID-19 pandemic stressful? A study on immediate mental health status and psychoneuroimmunity prevention measures of Chinese workforce. Brain Behav Immun. 2020;87:84-92. doi:10.1016/j. bbi.2020.04.055

23. Cowling BJ, Ali ST, Ng TW, et al. Impact assessment of non-pharmaceutical interventions against coronavirus disease 2019 and influenza in Hong Kong: an observational study. Lancet Public Health. 2020;5:e297-288. doi:10.1016/S2468-2667(20)30090-6

24. Block P, Hoffman M, Raabe IJ, et al. Social network-based distancing strategies to flatten the COVID-19 curve in a post-lockdown world. Nat Hum Behav. 2020;4:588-596. doi:10.1038/s41562-020-0898-6

25. Ahmad AR, Murad HR. The impact of social media on panic during the COVID-19 pandemic in Iraqi Kurdistan: online Questionnaire Study. J Med Internet Res. 2020;22:e19556. doi:10.2196/19556
Journal of Multidisciplinary Healthcare

\section{Publish your work in this journal}

The Journal of Multidisciplinary Healthcare is an international, peerreviewed open-access journal that aims to represent and publish research in healthcare areas delivered by practitioners of different disciplines. This includes studies and reviews conducted by multidisciplinary teams as well as research which evaluates the results or conduct of such teams or healthcare processes in general. The journal covers a very wide range of areas and welcomes submissions from practitioners at all levels, from all over the world. The manuscript management system is completely online and includes a very quick and fair peer-review system. Visit http://www.dovepress.com/testimonials. php to read real quotes from published authors. 